\title{
LA CAPACIDAD JURÍDICA DE LOS DISCAPACITADOS INTELECTUALES Y SUS DERECHOS COMO CONSUMIDORES EN ECUADOR SEGÚN la CONVENCIÓN DE los Derechos de las Personas con DISCAPACIDAD
}

\section{Robert Friend Macías}

Universidad de Especialidades Espíritu Santo UEES, docente de la Facultad de Derecho, Política y Desarrollo, Campus Samborondón, Guayaquil, Ecuador.

Correo electrónico: robertfriendm@gmail.com; robertfriend@uees.edu.ec

\section{María de los Ángeles ÁlaVa Díaz}

Universidad de Especialidades Espíritu Santo UEES,

alumna de la Facultad de Derecho, Política y Desarrollo, Campus Samborondón,

Guayaquil, Ecuador.

Correo electrónico:malavad@uees.edu.ec; ab.malavad@hotmail.com

Recibido / Received: 01/03/2019

Aceptado / Accepted: 26/03/2019

DOI: $10.18272 / \operatorname{lr} . v 6 i 1.1384$

\section{Citación}

Friend Macías, R. A., M. de los Ángeles Álava Díaz. «La Capacidad jurídica De Los Discapacitados Intelectuales Y Sus Derechos Como Consumidores En Ecuador Según La Convención De Los Derechos De Las Personas Con Discapacidad». USFQ Law Review, Vol. 6, n. ${ }^{\circ}$, agosto de 2019, p. 15, doi:10.18272/lr.v6i1.1384. 


\title{
RESUMEN
}

La presente investigación analiza el ordenamiento jurídico ecuatoriano relacionado con los derechos como consumidores de las personas con discapacidad intelectual en concordancia con la Convención para los Derechos de las Personas con Discapacidad, para lo cual se realiza una revisión bibliográfica de las leyes relacionadas, y un análisis de un caso real en Ecuador y una comparación con el Derecho de otros países. Lo anterior ha permitido identificar que existen algunas falencias que atentan contra los derechos de las personas con discapacidad intelectual como la limitación de la concepción médica para definir la discapacidad, así como la nueva concepción de capacidad jurídica y la existencia de términos relacionados con los discapacitados intelectuales que son discriminatorios y peyorativos dentro del Código Civil, lo que ha traído como consecuencia que diversos funcionarios públicos y operadores de justicia no tengan lineamientos claros respecto de la voluntad y autonomía de estas personas para poder representarse por sí mismas.

\section{Palabras clave}

discapacidad intelectual; sistema de capacidad; capacidad jurídica; autonomía de la voluntad; Derecho comparado.

\section{The legal capacity of intellectually disabled people and their rights in Ecuador according to the Convention on the Rights of Persons with Disabilities}

\begin{abstract}
This research analyses the Ecuadorian legal system related to the rights of persons with intellectual disabilities as consumers in accordance with the Convention on The Rights Of Persons With Disabilities, for which, it carries out a bibliographical review of the legal framework as well as to an analysis of a real case in Ecuador and a comparison with the law of other countries. This has allowed to identify that there are some flaws that threaten the rights of people with intellectual disabilities such as limiting the medical conception that defines disability, as well as the new conception of legal capacity and the existence of terms related to intellectually disability that are discriminatory and derogatory within the Civil Code. Consequently, various public officials and operators of justice do not have clear guidelines regarding the will and autonomy of this group of consumers people to be able to represent themselves.
\end{abstract}

\section{KEYWORDS}

intellectual disability, capacity system, legal capacity, autonomy of the will, comparative Law. 


\section{INTRODUCCIÓN}

Las personas con discapacidad están protegidas por diversas normas supranacionales las cuales generalmente contienen políticas de inclusión, accesibilidad y no discriminación en favor de este grupo. Sin embargo, hasta antes de la promulgación de la Convención sobre los Derechos de las Personas con Discapacidad (en adelante CDPD), no se trataba sobre la capacidad jurídica de estas personas ni los efectos jurídicos que producen los actos que ellos suscriben, por lo que, para la presente investigación, se ha considerado específicamente tratar sobre la capacidad jurídica de los discapacitados intelectuales.

Ecuador, por su parte, considera a las personas con discapacidad como sujetos de atención prioritaria de acuerdo al artículo 35 de la Constitución de la República, lo que permitió después promulgar la Ley Orgánica de Discapacidades, la cual fue publicada en el Registro Oficial No. 796 Suplemento de 25 de septiembre de 2012, cuya disposición reformatoria y derogatoria decimotercera, sustituye el término demente por el de discapacitado intelectual dentro de todo el ordenamiento jurídico ecuatoriano, con el fin de cumplir con el principio de igualdad que profesa la Carta Magna.

En razón de lo anterior y con el objetivo de actualizar la terminología, se reformaron 58 artículos del Código Civil, pero a pesar de aquello, se puede observar que existen aún términos ofensivos como loco, furioso, o la persistencia del término demente. Estos términos peyorativos son la menor de las deficiencias del marco jurídico ecuatoriano, pero son el punto de partida para identificar una problemática mayor. Básicamente, la debilidad más importante radica en la ausencia de una normativa clara y concisa que permita identificar la capacidad de ejercicio de los discapacitados intelectuales sobre la base de su grado de discernimiento y raciocinio. Esto ocasiona que derechos fundamentales les sean negados debido a suposiciones personales sin fundamento objetivo y técnico.

Así, jueces, notarios y demás funcionarios públicos, al no disponer de un marco claro sobre los actos jurídicos realizados por los discapacitados intelectuales, de manera discrecional, establecen límites para la ejecución de ciertos actos jurídicos, como la suscripción de contratos para la adquisición de bienes y servicios, lo cual será demostrado en este trabajo y evidenciado mediante un caso real que pareciese ser la regla general en aquellos países que mantienen una legislación que no protege la autonomía de la voluntad de las personas con discapacidad intelectual.

En consideración a la problemática citada, este artículo académico tiene como objetivo identificar las anomalías del marco jurídico ecuatoriano que violentan los derechos de las personas con discapacidad intelectual en su calidad de consumidores. De igual forma, se analizan las recomendaciones realizadas por la Orga- 
nización de las Naciones Unidas (en adelante ONU) en este tema y se contrastan con los aportes de catedráticos e investigadores de la materia. Finalmente, se realiza una descripción breve del marco jurídico de países como España y Argentina que han regulado un sistema de capacidades más incluyente para las personas con discapacidad intelectual.

\section{EVOLUCIÓN HISTÓRICA DEL SISTEMA DE CAPACIDADES Y LA DISCAPACIDAD INTELECTUAL SEGÚN LA CONVENCIÓN PARA LOS Derechos de los Discapacitados}

De acuerdo con Quinn y Degener,los primeros antecedentes sobre el reconocimiento de los derechos de los discapacitados surgieron en la década de los ańos cincuenta, gracias a la ONU, entidad que estableció normas internacionales en temas de educación, capacitación y distinción de personas con discapacidad ${ }^{1}$

Después de dos décadas, el criterio del marco jurídico internacional evolucionó a un sistema basado en derechos. De esta forma, el 20 de diciembre de $1971^{2}$, se genera la Declaración de los Derechos del Retrasado Mental proclamada por la Asamblea de las Naciones Unidas, a través de la Resolución 2856, en la cual, por primera vez, se afirma que "las personas discapacitadas deben gozar los mismos derechos que las personas sanas" 3 .

Posteriormente, en 1975, se lograron avances importantes en materia de discapacidad con la Resolución 3447, la cual se denominó como Declaración de los Derechos de los Impedidos, misma que reconoce, en su párrafo 5, que "los impedidos tienen derecho a medidas destinadas a permitirles lograr la mayor autonomía posible"s.

Sin perjuicio de lo anterior, el verdadero fortalecimiento del Derecho Internacional se dio entre 1983 y 1992, período declarado como Decenio de las Naciones Unidas para los Impedidos gracias a los resultados del Programa de Acción Mundial para los Discapacitados puesto en marcha en 1982. En este programa, se trató por primera vez la necesidad de que el Estado genere políticas que permitan la inserción del impedido en la sociedad 5 . Uno de los logros más importantes del programa antes referido se dio en el 2002, cuando se materializó la recomendación de la creación de una convención completa sobre los derechos de las personas con discapacidad en la Resolución 58/132, respaldada por 191

\footnotetext{
Quinn, Gerard., y Degener, Theresia. Aplicación de la autoridad moral. En Compilador o editor. Derechos Humanos y discapacidad: Uso actual y posibilidades futuras. Ginebra: Publicaciones de las Naciones Unidas, 2004, p. 24.

2 Barranco, María. Del Carmen., Cuenca, Patricia. y Ramiro, Miguel. "Capacidad jurídica y discapacidad: el artículo 12 de la Convención de Derechos de las Personas con Discapacidad”. Anuario Facultad de Derecho - Universidad de Alcalá, (2012), p. 53-80.

3 Declaración de los Derechos del Retrasado Mental, Resolución 2856 (1971).

4 Quinn, Gerard., y Degener, Theresia. Óp. cit., p. 24.

5 Organización Naciones Unidas. Historia de la discapacidad y las Naciones Unidas - Decenio de las Naciones Unidas para los Impedidos: 1983-1992. 14 de marzo de 2018. https://www.un.org/spanish/disabilities/default.asp?id=576 (acceso: 1/04/2019).
} 
países miembros. Como resultado de aquello, en el año 2006, se promulgó la Convención Internacional sobre los Derechos de las Personas con Discapacidad (en adelante CDPD) ${ }^{6}$.

La CDPD se convirtió en el instrumento más importante de Derecho Internacional en materia de discapacidad y está compuesta por 50 artículos que reconocen, protegen y promueven derechos fundamentales de los discapacitados en materia civil, política, social, económica y cultural ${ }^{7}$. La Convención ha motivado a que a los Estados partes, miembros de la ONU, actualicen sus marcos regulatorios, pero, sobre todo, la importancia de la Convención se manifiesta en la visibilización de la situación de los discapacitados que históricamente han sufrido segregación social que ha afectado su capacidad de ejercicio para poder representarse plenamente en los actos jurídicos que realizan ${ }^{8}$.

\section{LA DISCAPACIDAD EN ECUADOR Y LA CONVENCIÓN SOBRE LOS Derechos de las Personas con Discapacidad}

Según Galarza las primeras acciones promovidas por el Estado, en materia de discapacidad, se dieron en el ańo 1990 a pesar que aquellos esfuerzos fueron infructuosos. Posteriormente, en 1992, se creó, mediante la Ley 180, el Consejo Nacional de Discapacidades (Conadis). Sin embargo, debido a que, en aquella época, el marco jurídico nacional no consideraba a los discapacitados como personas de atención prioritaria, la entidad no tuvo el apoyo presupuestario ni político para generar acciones de impacto?

Entre 1993 y 2007, el país vivió momentos de inestabilidad política con nueve presidentes en el poder. Solo uno pudo terminar su mandato (Sixto Durán Ballén) y un triunvirato que gobernó durante un día. Por esta razón, no existió, no se generó una política social para la inclusión de personas con discapacidad ${ }^{10}$. Recién en 2008, Ecuador fue una de las primeras naciones que adaptó su marco jurídico tomando como referencia la Convención sobre los Derechos de las Personas con Discapacidad ${ }^{11}$. Estos cambios motivaron la creación de la Ley Orgánica de Discapacidades, publicada en el Registro Oficial No. 796 Suplemento de 25 de septiembre de $2012^{12}$. A pesar de aquello, estas acciones no fueron del todo

6 Convención sobre los Derechos de las Personas con Discapacidad (2006). https://www.un.org/esa/socdev/enable/documents/ tccconvs.pdf (acceso:18/03/2019).

7 Botero, Paola. "Discapacidad y estilos de afrontamiento: una revisión teórica". Revista Vanguardia Psicológica (2013), p. 197-213.

8 Bariffi, Francisco. 2008-2013: Cinco años de vigencia de la Convención Internacional sobre los Derechos De las Personas con Discapacidad. Mesa Redonda: Plena igualdad ante la Ley, capacidad jurídica y limitación de derechos. Ginebra: Publicaciones de la Organización de las Naciones Unidas, 2015, p. 9.

9 Galarza, Miranda. "Discapacidad intelectual: demanda por un análisis cultural y social crítico en Ecuador". Revista Sociológica de Pensamiento Crítico (2009), p. 179-202.

10 Albán, Diana. et al. "Política de atención a personas con discapacidad en el Ecuador: hacia un modelo de exportación". Revista Linea Sur (2013), p. 95-110.

11 Brogna, Patricia. Visiones y revisiones de la discapacidad (Compilación). México DF: Fondo de Cultura Económica, 2012, p. 10-45.

12 Ley Orgánica de Discapacidades. Registro Oficial No. 796 Suplemento de 25 de septiembre de 2012. 
efectivas porque, tras siete años de vigencia de la Constitución, se identificaron retos que deben ser aún superados ${ }^{13}$.

Estos retos se expresan en treinta y dos motivos de preocupación y treinta y seis recomendaciones de acuerdo con el informe de Observaciones Finales sobre Ecuador del 27 de octubre de 2014 creado por el Comité de las Naciones Unidas sobre los Derechos de las Personas con Discapacidad. Una de las preocupaciones de mayor relevancia es la concepción médica que fundamenta la definición del término discapacidad en la Ley Orgánica de Discapacidades. En este sentido, el texto de recomendación expone "la definición de persona con discapacidad enfatiza la restricción de capacidades y soslaya la dimensión social y relacional de la discapacidad"14.

Según el contexto anterior, Bariffi, expone en el marco de la Conferencia Internacional sobre los cinco años de vigencia de la Convención Internacional sobre los Derechos de las Personas con Discapacidad, que la condición de una persona es la puerta de acceso a la titularidad de los derechos, y al mismo tiempo, la capacidad jurídica, es la puerta de acceso al ejercicio de estos 15 . Sin un reconocimiento pleno de capacidad jurídica, no es posible acceder verdaderamente al ejercicio de los derechos humanos en general ${ }^{16}$.

\section{EL SISTEMA DE CAPACIDAD EN LA LEGISLACIÓN ECUATORIANA}

Ecuador, como Estado constitucional de derechos, establece el respeto, protección y garantía de los derechos humanos y consagra la atención prioritaria para aquellas personas pertenecientes a los grupos tradicionalmente excluidos, como lo son las personas con discapacidad, aplicando el principio de igualdad y no discriminación de manera transversal en cada una de sus políticas y acciones ${ }^{17}$.

En un intento de abarcar correctamente todos los aspectos de la condición jurídica de las personas con discapacidad, se realizaron cambios en el Reglamento a la Ley Orgánica de Discapacidades ${ }^{18}$ y en la Ley Orgánica de Defensa al Consumidor ${ }^{19}$, con el objetivo de ajustar a los preceptos constitucionales y a las recomendaciones emitidas por organismos internacionales como las Naciones Unidas en relación con lo contenido en la Convención Internacional sobre los Derechos de las Personas con Discapacidad. Sin embargo, los esfuerzos han sido infructuosos porque dejan

13 Salazar, Joab. Análisis de las politicas públicas y leyes que implementó el gobierno del Ecuador entre 2009 y 2017 en favor de la inclusión social de las personas con discapacidad a través del enfoque de capacidades de Amartya Sen y la ciudadanía universal de Martha Nuss. Tesis de Grado. Pontificia Universidad Católica del Ecuador, Quito, 2018, p. 54-69.

14 Comité sobre los Derechos Humanos de las Personas con Discapacidad (CRPD) - Ecuador 201. Observaciones finales sobre el informe inicial del Ecuador, 27 de octubre de 2014. http://acnudh.org/comite-sobre-los-derechos-de-las-personas-condiscapacidad-crpd-ecuador-2014/ (acceso: 11/01/2019).

15 Bariff, Francisco. 2015. Óp. cit., p. 9.

16 Martínez, Miguel. Acosta. Teoría general del acto jurídico y obligaciones. México DF: Porrúa, 2013, p. 56.

17 Pérez, Luis., y Andreu, Alberto. Inclusión, discapacidad y empleo: Algunas claves a través de 7 historias de vida caso Ecuador. Madrid: Cinta, 2014, p. 103.

18 Reglamento a la Ley Orgánica de Discapacidades. Registro Oficial No. 109 Suplemento de 27 de octubre de 2017.

19 Ley Orgánica de Defensa del Consumidor. Registro Oficial No. 116 Suplemento de 10 de julio de 2000. (última modificación 13 de octubre de 2011). 
abierta la posibilidad para que los jueces y demás funcionarios públicos, realicen interpretaciones sin disponer de lineamientos claros para tomar decisiones efectivas sobre la capacidad de ejercicio de las personas con discapacidad intelectual ${ }^{20}$.

\subsection{El Código Civil ecuatoriano}

El sistema de capacidad regulado en el Código Civil establece, en su artículo 1463 , que "son absolutamente incapaces los dementes, los impúberes y las personas sordas que no puedan darse a entender de manera verbal, por escrito o por lengua de señas" 21 . Como se observa, el Código Civil emplea el término dementes para las personas consideradas legalmente como incapaces absolutas, pero atendiendo al texto de la reforma que se realizó en la Ley Orgánica de Discapacidades, se sustituye dicho término por el de discapacitado intelectual por considerarlo peyorativo y discriminatorio. A pesar de los cambios, reformas y modificaciones realizadas en la normativa ecuatoriana, el Código Civil conserva, en la mayoría de sus artículos, la palabra demente y lo posiciona como el cuerpo legal con más imprecisiones en su redacción dentro del ordenamiento jurídico ecuatoriano ${ }^{22}$.

Asimismo, el Código Civil, en el artículo 486, contiene presunciones respecto de las limitaciones de los actos jurídicos del demente que, de acuerdo con lo expresado en líneas anteriores, actualmente se los denomina discapacitados intelectuales. De esta forma el Código Civil del Ecuador, en el artículo mencionado anteriormente, establece que los actos y contratos del demente, posteriores a la sentencia de interdicción, serán nulos, aunque se alegue que fueron ejecutados o celebrados en un intervalo de lucidez; $y$, por el contrario, los actos y contratos ejecutados o celebrados sin previa interdicción serán válidos, a menos de probarse que la persona que los ejecutó o celebró, estaba entonces privado del uso de la razón.

Respecto a aquello, Ospina presume que tales actos son válidos, porque la capacidad es la regla general en nuestro derecho, según ya quedó explicado, lo que no se opone a que se demuestre judicialmente que han sido celebrados en un momento en que el agente se encontraba en estado de enajenación mental y que, por tanto, son inválidos ${ }^{23}$.

Sin embargo, en contradicción con lo anterior, los dementes no interdictos tampoco tienen plena capacidad de ejercicio, ya que el mismo código, en su artículo 518 , indica que son incapaces para ejercer toda tutela o curaduría "los dementes, aunque no estén bajo interdicción" ${ }^{24}$, lo que evidencia que los discapacitados

20 Este argumento nace del análisis realizado en el presente documento, como consecuencia de la revisión bibliográfica y el análisis del caso.

21 Código Civil. Registro Oficial No. 46 Suplemento de 24 de junio de 2005 (última modificación 22 de mayo de 2016).

$22 \mathrm{Al}$ revisar el Código Civil, se puede observar con claridad que se menciona la palabra demente durante todo el cuerpo legal, generando ambigüedad en la interpretación normativa y por ende una posible afectación de los derechos en general de este grupo de personas.

23 Ospina, Fernández. Teoría general del contrato y del negocio jurídico. Bogotá: Temis, 2015, p. 88-94.

24 Código Civil. Eiusdem. Artículo 518. 
intelectuales se encuentran inmersos en una laguna legal respecto de la validez de sus actos jurídicos.

Para concluir este tema, se ha demostrado a través de los artículos antes analizados, una de las tantas contradicciones contenidas en el Código Civil y la inseguridad jurídica que envuelve los actos realizados por los discapacitados intelectuales. Por esta razón, se debe precisar que una persona discapacitada intelectual no siempre puede considerarse como incapaz absoluto, ni tampoco tiene el mismo significado y connotación el término discapacidad e incapacidad ${ }^{25}$, ya que mientras una persona con discapacidad intelectual privada del uso de la razón no haya sido declarada en interdicción judicial, la presunción de validez de sus actos jurídicos dependerá de la aprobación de la falta de autonomía de su voluntad a través de métodos científicos ${ }^{26}$.

Finalmente, el Consejo Nacional para la Igualdad de Discapacidades emitió la Resolución 011-ST-2018 publicada en el Registro Oficial No. 435 de 25 de febrero de 2018, en que se establece que las personas con discapacidad física, auditiva, visual, intelectual y psicosocial son "legalmente capaces para poder celebrar actos y contratos por sí solos; conforme a lo dispuesto en el artículo 5 y en los numerales 2, 3, 4 y 5 del artículo 12 de la Convención sobre los Derechos de las Personas con Discapacidad"27. Respecto a esta Resolución, es preciso manifestar que no resuelve la inseguridad jurídica que engloban los actos de las personas con discapacidad intelectual, que es lo que nos incumbe en el sentido de que se ha demostrado hasta ahora que el problema no se solucionará hasta que no exista una completa reforma al sistema de capacidad del Código Civil a la luz de lo consagrado en el artículo 12 de CDPD.

\subsection{Ley Orgánica de Discapacidades}

La discapacidad se considera como una condición adquirida por factores congénitos o por problemas externos ${ }^{28}$, tales como accidentes que causan cambios físicos o intelectuales momentáneos o permanentes en una persona, determinando un estilo de vida diferente que no se ajusta al convivir diario de la sociedad y, por ende, necesita de una atención diferenciada en todos los ámbitos, incluso en las concepciones legales ${ }^{29}$.

25 Villarreal, Carla. "El reconocimiento de la capacidad jurídica de las personas con discapacidad mental e intelectual y su incompatibilidad con los efectos jurídicos de la interdicción y la curatela". Revista Jurídica de la Pontificia Universidad Católica del Perú (2014), p. 18-59.

26 Los métodos científicos se refieren a metodológicas de carácter médico que efectivamente prueben que una persona no está en la capacidad de tomar decisiones coherentes por afectaciones de índole fisiológicas o psicológicas.

27 Consejo Nacional para la Igualdad de Discapacidades Resolución No. 011-ST-2018. Artículo 1. Registro Oficial No. 345 de 25 de febrero de 2018.

28 Monje, Jose. "Misión «Manuela Espejo», paradigma de la solidaridad convertida en política de Estado en Ecuador". Revista Cubana de Salud Pública (2013), p. 598-608.

29 Buitrago, Adriana., Giraldo, Yaniza., y Silva, Alba. "La discapacidad en el ordenamiento jurídico colombiano". Revista Republicana (2015), p.135-158. 
Según el artículo 6 de la Ley Orgánica de Discapacidades, una persona con discapacidad es toda aquella que "ve restringida permanentemente su capacidad biológica, psicológica y asociativa y, como resultado, no puede ejercer actividades sociales de manera normal" 30 . Esta definición es limitada y restrictiva porque al usar el término permanentemente, no considera aspectos importantes como el hecho que una persona con discapacidad intelectual puede obtener tratamiento y mejorar su condición

En este sentido, es indispensable citar el documento titulado Informe Mundial sobre Discapacidad publicado por la Organización Mundial de la Salud, que expone una debilidad del marco jurídico alrededor del mundo por cuanto las definiciones jurídicas sobre la discapacidad no consideran la evidencia médica que indica que las personas que sufren ciertas patologías que desembocan en discapacidad mental, pueden mejorar su condición gracias a tratamiento y terapia ${ }^{31}$. Por ejemplo, una persona que sufre de síndrome de Down, que ha tenido educación y tratamiento especial, puede alcanzar estudios de cuarto nivel. Entonces, a pesar de que su capacidad ha sido reducida por su patología, esto no ha sido impedimento para ejercer actividades académicas normales ${ }^{32}$.

Una debilidad de la Ley Orgánica de Discapacidades es que menciona varios criterios ambiguos para definir la incapacidad física o psicológica de una persona. De esta forma, el artículo 6, establece lo siguiente:

Para efectos de esta ley, se considera persona con discapacidad a toda aquella que, como consecuencia de una o más deficiencias físicas, mentales, intelectuales o sensoriales, con independencia de la causa que le hubiere originado, ve restringida permanentemente su discapacidad biológica, psicológica y asociativa para ejercer una o más actividades esenciales de la vida diaria, en la proporción que establezca el reglamento ${ }^{33}$.

Esta misma definición se encuentra incorporada en el reglamento de la ley mencionada ut supra, por lo que nada aporta acerca de la validez de los actos realizados por un discapacitado intelectual. Lo que debe destacarse en esta norma es que el Ministerio de Salud Pública y el Consejo Nacional de Discapacidad utiliza el modelo de baremo espańol, el mismo que es uno de los modelos más completos que especifica valoración y criterios para establecer discapacidad física o intelectual de una persona usando como criterios la disminución de la capacidad laboral o autonomía de vivir por sí solo, así como el análisis de la sintomatología psicopatológica universalmente $\operatorname{aceptada}^{34}$. No obstante, este sistema no se ajusta totalmente a las particularidades del contexto social ecuatoriano, por lo que surgen malinterpretaciones.

30 Ley Orgánica de Discapacidades. Eiusdem. Artículo 6.

31 Organización Mundial de la Salud. Informe mundial sobre la discapacidad. Ginebra: Organización Mundial de la Salud, 2011, p. 9-23.

32 Ruiz, Emilio. "Evaluación de la capacidad intelectual en personas con síndrome de Down". Revista Española de Investigación e Información sobre el Sindrome de Down (2001), p. 80-88.

33 Ley Orgánica de Discapacidades. Eiusdem. Artículo 6.

34 Salazar, Joab. Óp. cit., p.54-69. 
En general, el problema que tiene la Ley de Discapacidades y su Reglamento es que solamente plantean beneficios de índole socioeconómica ${ }^{35}$, pero no determina, según el grado de discapacidad de la persona, la capacidad de ejercicio y la validez de sus actos jurídicos de acuerdo con su grado real de discapacidad intelectual. Como consecuencia, se argumenta que la debilidad de la Ley genera que jueces y demás funcionarios públicos usen a discrecionalidad su criterio para determinar la incapacidad jurídica ya que el Código Civil tampoco resuelve la problemática.

\subsection{Proceso de acreditación de las personas con DISCAPACIDAD}

El marco jurídico ecuatoriano establece mecanismos para categorizar a los discapacitados en general, de acuerdo con diferentes grados porcentuales de discapacidad, para lo cual el Ministerio de Salud Pública y el Consejo Nacional de Discapacidad utilizan el modelo español mencionado anteriormente ${ }^{36}$. Sin perjuicio de lo anterior, el resultado de este procedimiento se limita a la emisión de una credencial que representa el grado de discapacidad evidente o visible de una persona, información incompleta que no sirve a jueces o notarios para conocer si es que aquella persona puede usar su razonamiento lógico, que es lo primordial para tomar decisiones coherentes.

De acuerdo con la Ley de Discapacidades en su artículo 11, una vez realizada la calificación de las personas con discapacidad y el correspondiente registro por parte de la unidad competente del Sistema Nacional de Salud, la autoridad sanitaria deberá inmediatamente enviar dicha información a la Dirección General de Registro Civil, Identificación y Cedulación, para que, de esta manera, se incluya en la cédula de ciudadanía la discapacidad de la persona, su porcentaje, tipo y nivel ${ }^{37}$.

No obstante, a pesar que la normativa es clara, en la práctica, no existe ningún acuerdo institucional entre el Registro Civil y el Ministerio de Salud Pública ${ }^{38}$ sobre el cruce de información de las personas que tienen algún tipo de discapacidad ya sea física o intelectual y, más grave aún, cuando la persona con discapacidad informa de su condición al Registro Civil, si bien es cierto que se incluyen sus datos en la ficha cedular, al momento de imprimir la cédula, los datos sobre sobre su discapacidad no siempre se reflejan en el documento de identificación o, en el caso más común, la persona con discapacidad no actualiza su cédula.

35 Exenciones tributarias para importaciones de vehículos, descuentos en el pago de servicios básicos y tarifas preferenciales para la adquisición de bienes y servicios privados.

36 Espinosa, Carlos., Gómez, Victor., y Cañedo, Carlos. "El acceso y la retención en la educación superior de estudiantes con discapacidad en Ecuador". Revista Formación Universitaria (2012), p. 27-38.

37 Ley Orgánica de Discapacidades. Eiusdem. Artículo 11.

38 No se encontró ningún documento en los repositorios digitales, ni tampoco se remitieron los documentos al realizar las consultas a los servidores públicos de las entidades. 
De esta manera, se concluye que, a pesar que la cédula de ciudadanía ${ }^{39}$ es el único documento habilitante que sirve a las personas con discapacidad para acogerse a la Ley de Discapacidades y es el único documento que les permite tener un beneficio para todo trámite público o privado, no existen los instrumentos legales que permitan un correcto traslado de información entre las entidades competentes, de manera que no existe herramientas que permitan la plena inclusión de los discapacitados intelectuales.

\subsection{Ley Orgánica de Defensa del Consumidor}

El artículo 4 de la Ley Orgánica de Defensa del Consumidor establece que, entre los Derechos de los Consumidores, además de los especificados en la Constitución de la República, tratados o convenios internacionales, legislación interna, principios generales del Derecho y costumbre mercantil, se encuentran el derecho a un trato transparente, equitativo y no discriminatorio por parte de los proveedores de bienes o servicios, especialmente en lo referido a las condiciones óptimas de calidad, cantidad, precio, peso y medida ${ }^{40}$.

De igual forma, el artículo 55 eiusdem, prescribe que es un abuso "aprovecharse dolosamente de la edad, salud, instrucción o capacidad del consumidor para venderle determinado bien o servicio" ${ }^{41}$. En este sentido, si bien es cierto que a lo largo del presente documento se ha mencionado que no es lo mismo discapacidad que incapacidad, y que no toda persona con discapacidad intelectual es incapaz absoluto, la interrogante que surge de este escenario es: ¿̨las personas con discapacidad intelectual pueden ser consideradas como consumidores?

La respuesta puede ser sencilla desde el punto jurídico, debido a que hasta no pesar sobre ellos una sentencia de interdicción, en definitiva, son legalmente capaces para realizar actos jurídicos y consecuentemente ser consideradas consumidores. Esta postura puede ser débil ya que la regulación objeto de análisis, trata de la misma forma a todos los discapacitados intelectuales sin considerar el grado de voluntad y raciocinio de estos.

Por lo anterior, un discapacitado intelectual con un carné que refleje un grado de discapacidad intelectual del $70 \%$ es plenamente capaz según la norma que regula los derechos del consumidor mientras no tenga sentencia de interdicción visualizando más la problemática que propone esta investigación. A continuación, se plantea un caso real en donde se podrá apreciar las dificultades que una persona con discapacidad intelectual leve tuvo que enfrentar por las falencias del sistema de capacidades en Ecuador y de todas las normas conexas que regulan el tema.

39 Ley Orgánica de Discapacidades. Eiusdem. Artículo 12.

40 Ley Orgánica de Defensa del Consumidor. Eisdem. Artículo 4.

41 Eiusdem. Artículo 55. 


\section{ANÁlisis de CASO}

El caso ${ }^{42}$ ocurrió en la ciudad de Guayaquil, cuando la Srta. María Paulina García León Hing obtuvo el financiamiento aprobado por el Banco del Instituto Ecuatoriano de Seguridad Social (en adelante BIESS) para la adquisición de una vivienda y, para culminar con el trámite de compraventa, dicha institución la derivó a una notaría para formalizar la escritura. La titular de la Notaría 53 de Guayaquil, abogada Kelly Sempertegui Zambrano, no autorizó y se negó a dar fe y solemnizar el acto notarial de escritura de venta entre el BIESS y la Srta. León, alegando que esta última tenía un grado moderado de discapacidad intelectual del $35 \%$ según se desprendía de la copia del carné del Conadis, por lo que le manifestó que debía tener un curador que interviniera en el acto jurídico para celebrarlo.

Luego de aquello y por disposición de la notaría, la ciudadana presentó, ante la justicia ordinaria, la solicitud de nombramiento de curador, pero fue inadmitido por la abogada Dorinda Perla Rivera Cárdenas, jueza de la Unidad Judicial Norte de Familia, Mujer, Niñez y Adolescencia con número de juicio 09201-201600773, quien alegó que la discapacidad acreditada por el Ministerio de Salud Pública del Ecuador de $35 \%$, no justifica el nombramiento de un curador. Ante esta situación la ciudadana no pudo celebrar el contrato, en razón de que caducó el plazo señalado por el BIESS para su suscripción.

El 29 de septiembre de 2016, la Srta. María Paulina García León Hing acudió a la Defensoría del Pueblo a denunciar la violación a sus derechos como consumidora en razón de que se le negó formalizar y suscribir una escritura de compraventa de una casa en la Notaría 53 del cantón Guayaquil, por tener $35 \%$ de discapacidad intelectual. Los argumentos indican que le han sido vulnerados los derechos establecidos en el artículo 4 de la Ley Orgánica de Defensa del Consumidor debido a que, a través de un juicio de valor, la notaria indicó que no puede realizar el acto jurídico para formalizar la compraventa de un bien, negándole el servicio. La Defensoría del Pueblo admitió el trámite con número de expediente 2016-17448$\mathrm{xxx}^{43}$ de conformidad a lo establecido en el artículo 215 de la Constitución de la República del Ecuador. El 07 de octubre de 2016 se realizó la audiencia en donde comparecen las dos partes. La Notaría pidió disculpas públicas, manifestando que no fue su intención vulnerar derechos y, de la transcripción del Acta levantada en dicha audiencia, manifestó: "Simplemente cumplí con las formalidades que determina la ley para el cumplimiento y celebración de escrituras públicas". De los dichos de la Notaría, se desprende que esta funcionaria pública, por falta de claridad del ordenamiento jurídico ecuatoriano sobre la capacidad de ejercicio de los discapacitados intelectuales, vulnera derechos constitucionales, lo cual en ninguna circunstancia debió ocurrir.

42 Defensoría Pública, Expediente 2016-17448. Resolución de 7 de octubre de 2016.

43 No se pública el número de expediente completo con el fin de precautelar la privacidad de los actores. 
Es claro que existe un vacío legal para la actuación de los notarios y demás funcionarios públicos frente a este tipo de casos por lo que se debería reformar el Código Civil y la Ley Orgánica de Discapacidades y su Reglamento proponiendo un nuevo sistema de capacidad que garantice también los derechos que tienen como consumidores estas personas.

\section{LEGISLACIÓN COMPARADA}

\subsection{El SISTEMA DE DISCAPACIDADES ARGENTINO}

El 1 de agosto de 2015 entró en vigor la reforma al Código Civil argentino, que trajo consigo cambios sustanciales en la doctrina que norma las relaciones en la sociedad argentina, especialmente en materia de discapacidad. La nueva normativa se adaptó a los preceptos instituidos en la Convención sobre los Derechos de las Personas con Discapacidad, que fue aprobada y ratificada por el país en el año 2008 mediante ley $26378^{44}$.

Bariff, principal exponente que analiza el sistema de capacidad del Código Civil argentino, determina que la nueva concepción judicial en materia de discapacidad basada en los derechos humanos permite el respeto de la dignidad inherente, además del respeto a la libertad de tomar decisiones propias, y del respeto por las diferencias y aceptación de las personas discapacitadas en la sociedad en igualdad de oportunidades ${ }^{45}$.

El caso argentino presenta muchas ventajas en comparación a la legislación ecuatoriana. Por un lado, los jueces tienen la capacidad de declarar incapaz a una persona en dos formas: absoluta y restringida ${ }^{46}$. Se declara incapaz a una persona con discapacidad mental cuando tiene una falta absoluta de control para dirigirse a sí mismo o a sus bienes. En cambio, el juez dicta capacidad restringida, cuando la persona no presenta igual gravedad de condiciones que una persona incapaz, y solo tiene límites para realizar algunos actos que deben ser expresados por el juez ${ }^{47}$.

Por otro lado, la ley de Argentina en tema de discapacidad tiene un sistema de apoyo al ejercicio de la capacidad que Ecuador no lo tiene. Este se encuentra prescrito en el artículo 43 del Código Civil argentino, el cual establece que se entiende por apoyo a cualquier medida judicial y extrajudicial que facilite a la persona dirigirse. La persona interesada que necesite apoyo para realizar actos jurídicos o administrar sus bienes puede proponer al juez que le designe a una o

44 Pugliese, María. Rosa. "Las revistas jurídicas: un instrumento didáctico para el estudio de la evolución del derecho en la Argentina”. Revista sobre enseñanza del Derecho (2015), p. 75-105.

45 Bariffi, Francisco. "El Régimen de Incapacidad del Código Civil argentino a la luz de la Convención Internacional sobre los Derechos de las Personas con Discapacidad". Red Iberoamericana de Expertos en la Convención de los Derechos de las Personas con Discapacidad (2014), p. 107-133.

46 Acosta, Miguel. Teoría general del acto jurídico y obligaciones. México: Editorial Porrúa, 2013, p. 36.

47 Rodríguez, Antonio., y Vázquez, Aranzazu. "Revisión y crítica de la valoración del dańo estético. Propuesta de un nuevo baremo". Cuadernos de Medicina Forense (2014). p. 23-35. 
más personas de confianza, para que estas puedan dirigirlo y apoyarlo en todo lo relacionado con el ejercicio de sus derechos ${ }^{48}$.

Sin embargo, lo más importante de la legislación argentina radica en la posibilidad que tiene el juez para levantar la incapacidad restringida o absoluta en caso que se detecte a través de tratamientos médicos una mejoría de la persona ${ }^{49}$. Esto ayuda a profundizar y mejorar el sistema de capacidad, y permite dar paso a una posible recuperación del paciente con tratamiento médico; lo cual no se da en la legislación ecuatoriana.

En la actualidad, se encuentra en debate el Proyecto de Ley 4845-D-2017 donde se discute un reglamento que adecue un modelo que englobe los distintos apoyos para las personas con discapacidad. Los beneficios de este proyecto se enfocan en consolidar en un solo cuerpo legal el apoyo formal para sostener la capacidad jurídica, vida independiente y los programas y servicios de apoyo que se ven contenidos en el Título II del documento, el mismo que será incorporado directamente al Código Civil y de Comercio $^{50}$. Hasta marzo de 2019, el proyecto continúa en debate, y se ha estancado principalmente por el cambio de visión política del gobierno, así como también los ajustes económicos dados en Argentina ${ }^{51}$.

Se concluye que el régimen de capacidades graduales es una metodología flexible, que elimina el riesgo de restringir derechos a personas discapacitadas intelectuales que probablemente puedan actuar y tomar decisiones de manera coherente a pesar que, de manera preliminar, pueda suponerse que está incapacitado para aquello. Todo el sistema se refuerza con la metodología que permite a las autoridades argentinas determinar la capacidad jurídica, la cual es el baremo, metodología diseñada para ser utilizada por peritos médicos especializados en valoración de daños corporales y psíquicos, en el marco del Derecho común. Asimismo, los autores manifiestan que los rangos de valores para determinar incapacidad son tres: leve, moderada y grave, acompañada de criterios y explicaciones desde el punto de vista médico sobre la realidad y el futuro del incapacitado. Adicionalmente se establece un porcentaje en relación con la totalidad del individuo analizado ${ }^{52}$.

\subsection{EL SISTEMA DE DISCAPACIDADES ESPAÑOL}

La normativa espańola tiene cierta similitud con la ecuatoriana en cuanto a la realidad de las personas con discapacidad, las cuales constituyen un sector de la

48 Valencia, Cristina. y Berna, María. Elisa. "Institucionalidad y marco legislativo de la discapacidad en el Ecuador". Comisión Económica para América Latina y el Caribe (2016), p. 100-107.

49 Rositto, Sebastián. "Estado de la educación superior argentina a tres ańos de la ratificación de la Convención sobre los Derechos de las Personas con Discapacidad”. Red Iberoamericana de Expertos en la Convención (2014), p.104-129.

50 Giavarino, Magdalena. "La recepción del Sistema de Apoyos en el Nuevo Código Civil y Comercial". Estudios de Derecho Privado (2017), p. 115-129.

51 Trámite Parlamentario No 122- Expediente 4845-D-2017: Sistema de Apoyos para Personas con Discapacidad. Creación, 2019. https://www.diputados.gob.ar/proyectos/proyectoTP.jsp?exp=4845-D-2017 (acceso 01/04/2019).

52 Rodríguez, Antonio., y Vázquez, Aranzazu. Óp. cit. p. 23-35. 
población con características similares, es decir, que todas, en diferentes dimensiones, necesitan o precisan de protección en el ejercicio de los derechos huma$\operatorname{nos}^{53}$. La normativa también establece el régimen de infracciones y sanciones que buscan persuadir para que se den en la sociedad las condiciones básicas en materia de igualdad de oportunidades, no discriminación y accesibilidad universal de las personas con discapacidad ${ }^{54}$.

Asimismo, el artículo 200 del Código Civil español, al hablar de incapacidad, engloba varios aspectos que determinan la facultad de autogobernarse de los discapacitados debido a criterios médicos que permiten concluir si el individuo puede insertarse o adaptarse con la sociedad que lo rodea y enfrentar por sí solo los problemas que se le presentan. En razón de aquello, el juez tiene la facultad de declarar la limitación de los actos jurídicos que puede realizar la persona discapacitada dependiendo del tipo y grado de incapacidad que haya arrojado el baremo, instrumento mencionado en líneas anteriores ${ }^{55}$.

Esta figura jurídica descrita en el párrafo anterior, recibe el nombre de Capacidad Modificada Judicialmente, que, en resumen, permite al juez valorar de manera integral al discapacitado intelectual y le otorga una tercera persona o institución que lo represente en ciertos actos jurídicos. ${ }^{56} \mathrm{El}$ sistema de capacidad español se ve fielmente reflejado en el artículo 2 de la Ley de Protección Patrimonial de las Personas con Discapacidad que prescribe que estas personas tienen el beneficio de proteger su patrimonio basándose en parámetros médicos como, por ejemplo, lo refiere el literal a) de dicho artículo, el cual considera que las personas afectadas con una minusvalía psíquica igual o superior al $33 \%$ gozarán del beneficio de protección de su patrimonio ${ }^{57}$.

\section{Conclusiones}

Del análisis desarrollado en el presente documento, se desprenden varias conclusiones. En primer lugar, a pesar de la disposición reformatoria y derogatoria decimotercera de la Ley Orgánica de Discapacidad, el Código Civil ecuatoriano aún mantiene términos discriminatorios al referirse a las personas discapacitadas intelectuales, lo que demuestra que no solo basta con intentar cambiar la terminología del Código Civil, sino que existe la necesidad de modificar el sistema de capacidad que rige actualmente en Ecuador.

53 Schalock, Robert. "La nueva definición de discapacidad intelectual, apoyos individuales y resultados persona". Revista Española sobre Discapacidad Intelectual (2014), p. 22-39.

54 Heras, María. Del Mar. "Nuevos instrumentos jurídicos en la protección de las personas incapaces en el ordenamiento jurídico español: hacia una mayor flexibilización de las instituciones tradicionales". Revista del Instituto de Ciencias Jurídicas de Puebla (2015), p. 78-96.

55 Marín, Carlos. La integración jurídica y patrimonial de las personas con discapacidad psíquica o intelectual. Madrid: Universitaria Ramón Areces, 2012, p. 17-39.

56 García, Ignacio. Serrano. Protección patrimonial de las personas con discapacidad. Madrid: Iustel, 2015, p. 49.

57 Marín, Carlos. Óp. cit., p. 17-39. 
De igual forma, las falencias encontradas en el sistema de capacidad ecuatoriano no solo provoca inseguridad jurídica en la relación contractual entre el discapacitado intelectual y el proveedor de bienes y servicios, sino que también genera incertidumbre e incluso abuso de poder de funcionarios públicos que, por no contar con normativa clara, no saben cómo actuar, lo que termina vulnerando el derecho como consumidor de las personas con discapacidad intelectual.

Finalmente, al realizar el análisis de derecho comparado entre España, Argentina y Ecuador se concluye que el sistema de baremo usado en Argentina y Espańa para determinar diferentes grados de discapacidad intelectual, a través de la medición de la capacidad de razonamiento lógico es una metodología eficaz para determinar la capacidad de ejercicio de estas personas que debe implementarse en el sistema judicial ecuatoriano.

\section{Propuesta}

Se plantean tres propuestas para solventar este vacío y problemática:

1. Presentar un proyecto de reforma al Código Civil, la Ley Orgánica de Discapacidades y su Reglamento para que, en estos, consten los grados de discapacidad, estableciéndose qué actos puede realizar la persona con discapacidad intelectual. Esta reforma garantiza el derecho constitucional a la seguridad jurídica de las personas con discapacidad intelectual y también cumplir con lo contenido en los Tratados Internacionales de derechos humanos como lo hizo Argentina en su reforma al Código Civil que incluso unificó con el Código Comercial para proteger el derecho de propiedad de las personas con discapacidad.

2. El Ministerio de Salud Pública debería actualizar el sistema de baremo tomando como referencia el de Espańa y Argentina, con el objetivo de disponer insumos que permitan conceptualizar los efectos en la capacidad de razonamiento de acuerdo con los grados de discapacidad.

3. Una salida jurídica más allá de la reforma legal es que, mediante un Acuerdo Ministerial entre el Ministerio de Salud Pública y el Consejo de la Judicatura, se coordine que una vez resuelto el informe de discapacidad pertinente con el porcentaje de discapacidad, el organismo competente, antes de que emita el carné de discapacidad, retenga la cédula de ciudadanía del sujeto con discapacidad intelectual y, paralelamente, envíe el expediente y el informe de discapacidad a la Corte Provincial del domicilio de la persona con discapacidad intelectual para que sea sorteado a alguno de los jueces de lo Civil y, de oficio, se inicie el proceso para declarar la interdicción parcial o total según corresponda. 